\title{
Photoacoustic Detection of Short-Chained Hydrocarbon Isotopologues ${ }^{\dagger}$
}

\author{
Alain Loh ${ }^{1,2}$ and Marcus Wolff ${ }^{1, *}$ \\ 1 Hamburg University of Applied Sciences, Department of Mechanical and Production Engineering, Heinrich \\ Blasius Institute for Physical Technologies, Berliner Tor 21, 20099 Hamburg, Germany; \\ alain.loh@haw-hamburg.de \\ 2 University of the West of Scotland, School of Computing, Engineering \& Physical Sciences, High Street, \\ Paisley PA1 2BE, UK \\ * Correspondence: marcus.wolff@haw-hamburg.de; Tel.: +49-40-42875-8624 \\ + Presented at the 7th International Symposium on Sensor Science, Napoli, Italy, 9-11 May 2019. \\ Published: 15 July 2019
}

\begin{abstract}
We report, to our knowledge, the first optical detection of the main isotopologues of short-chained hydrocarbons. The sensor system is based on photoacoustic (also known as optoacoustic) spectroscopy (PAS, OAS). This technique takes advantage of the fact that absorbed electromagnetic radiation is partially transferred into kinetic energy via inelastic molecular collisions. This is equivalent to a temperature increase of the irradiated volume. If the radiation is modulated, a pressure wave with an amplitude proportional to the concentration of the absorbing molecules is generated, the so called PA (OA) signal. Two continuous wave (cw), thermoelectrically cooled (TEC), distributed feedback interband cascade lasers (DFB-ICLs) with emission wavelengths around 3.33 and $3.38 \mu \mathrm{m}$, respectively, serve as light sources. The PA signal is detected with a microphone and phase-sensitively amplified. The new sensor is applied for the stable carbon isotope-selective analyses of methane $\left(\mathrm{CH}_{4}\right)$, ethane $\left(\mathrm{C}_{2} \mathrm{H}_{6}\right)$ and propane $\left(\mathrm{C}_{3} \mathrm{H}_{8}\right)$. We report first measurements of ${ }^{12} \mathrm{C}_{2} \mathrm{H}_{6},{ }^{13} \mathrm{C}^{12} \mathrm{CH}_{6}$ and ${ }^{13} \mathrm{C}_{2} \mathrm{H}_{6}$ as well as of ${ }^{12} \mathrm{C}_{3} \mathrm{H}_{8}$ and ${ }^{13} \mathrm{C}^{12} \mathrm{C}_{2} \mathrm{H}_{8}$, all at approximate room temperature and atmospheric pressure. The listed isotopologues were selected because of their importance for numerous applications from atmospheric and planetary research to natural gas exploration.
\end{abstract}

Keywords: photoacoustic; spectroscopy; PAS; ethane; propane; carbon isotope; interband cascade laser; ICL; mid-infrared; MIR

\section{Introduction}

The measurement of hydrocarbon concentrations is essential to many applications from medical diagnostics and environmental research to natural gas exploration and planetary research [1-3]. In many cases, even the isotopic composition of a certain hydrocarbon has to be known to acquire certain information. The measurement of the methane isotope ratio $\left({ }^{13} \mathrm{CH}_{4}:{ }^{12} \mathrm{CH}_{4}\right)$, for instance, is critical to understanding the earth's carbon cycle [4].

Anthropogenic fossil fuel consumption generates approximately 8 gigatons of atmospheric carbon per year ( $\mathrm{GtC} /$ year). The arctic permafrost reservoir, however, is estimated to enclose at least $600 \mathrm{GtC}$ while the earth's oceans contain more than $11,000 \mathrm{GtC}$. A release of only a small fraction of the oceanic or permafrost reservoirs due to a temperature increase of the polar troposphere would lead to serious climate effects. Evidence for previous outflow of hydrocarbons from these sources is provided. Their isotope ratio allows tracing the outflows back to their various ecological or anthropogenic sources [4]. The mixing ratios of ethane and other non-methane hydrocarbons (NMHC) are useful indicators of atmospheric oxidation and transport processes on regional up to 
global scales. Although the number of NMHC isotopologue studies is still quite limited, the stable carbon isotope ratio measurements can provide additional insight into its sources, sinks and distribution in the atmosphere and allows estimating the photochemical age of each hydrocarbon. Altogether this information can help verify and constrain atmospheric models [5-7].

For the past 30 years, the gold standard for the detection of carbon isotopes has been the isotope-ratio mass spectrometry (IRMS). This technique is extraordinarily precise but expensive and quite complex and, therefore, usually carried out at an off-site facility, which makes real-time and in-situ measurements impossible. Furthermore, the hydrocarbon must be converted into $\mathrm{CO}_{2}$ by burning prior to analysis which destroys the sample and makes the method an indirect one [8].

A further development of the isotope ratio measurement techniques is, therefore, highly desirable. In a previous study, infrared absorption cross sections of the ethane and propane isotopologues were measured in the mid-infrared (MIR) range using an FTIR spectrometer [9]. The aim of this project is to develop an optical sensor that allows direct isotope-selective measurement of short-chained hydrocarbon.

\section{Materials and Methods}

The new analyzer applies distributed feedback interband cascade lasers (DFB-ICLs). These recently introduced emission sources enable continuous wave radiation in the MIR between $3 \mu \mathrm{m}$ and $6 \mu \mathrm{m}$ at room temperature operation [10]. This spectral region coincides with the strongest absorption of hydrocarbons. The lasers are compact and easy to use and their intrinsic DFB structure allows continuous and mode-hop free wavelength tuning with a spectral linewidth below $10 \mathrm{MHz}$. Due to its advantageous properties, photoacoustic spectroscopy (PAS) is applied [11]. This technique is based on the absorption of modulated radiation and its transformation into a sound wave [12,13]. As an offset-free technique, it enables extremely high detection sensitivity. Figure 1 shows the experimental setup as block diagram.

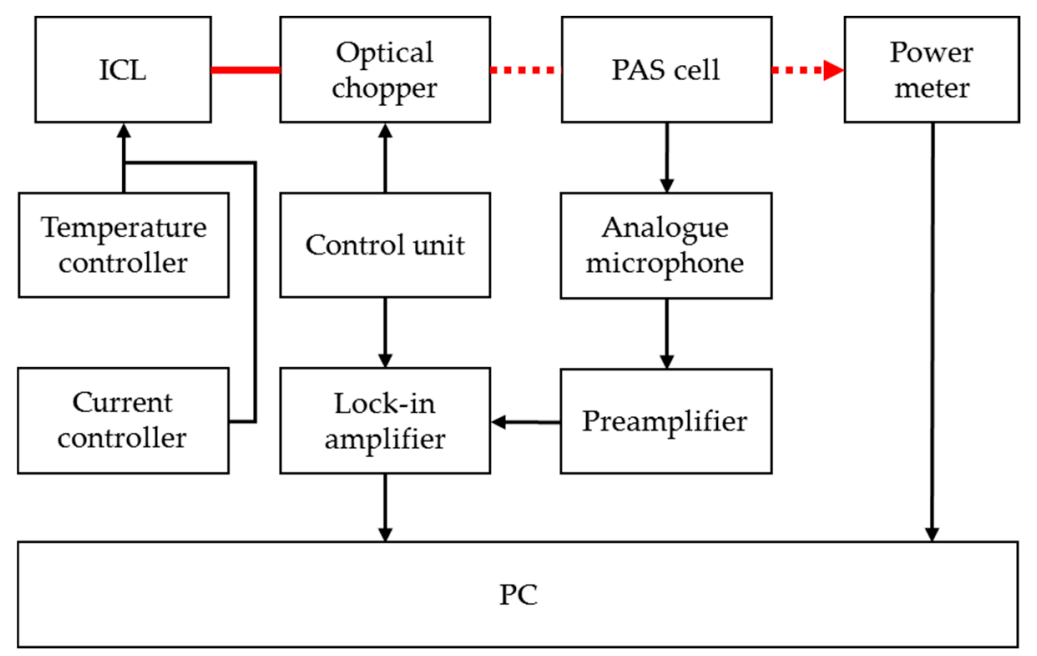

Figure 1. Experimental setup of the photoacoustic sensor system.

\section{Results}

Measurements were performed on the main stable carbon isotopologues of methane $\left(\mathrm{CH}_{4}\right)$, ethane $\left(\mathrm{C}_{2} \mathrm{H}_{6}\right)$ and propane $\left(\mathrm{C}_{3} \mathrm{H}_{8}\right)$. Figure 2 shows exemplary photoacoustic spectra of ${ }^{12} \mathrm{C}_{2} \mathrm{H}_{6}$ and ${ }^{13} \mathrm{C}_{2} \mathrm{H}_{6}$, each approximately $1 \%$ in $\mathrm{N}_{2}$, and of a mixture of the two isotopologues (each $1 \%$ in $\mathrm{N}_{2}$ ). All measurements were recorded at approximate room temperature and atmospheric pressure. 


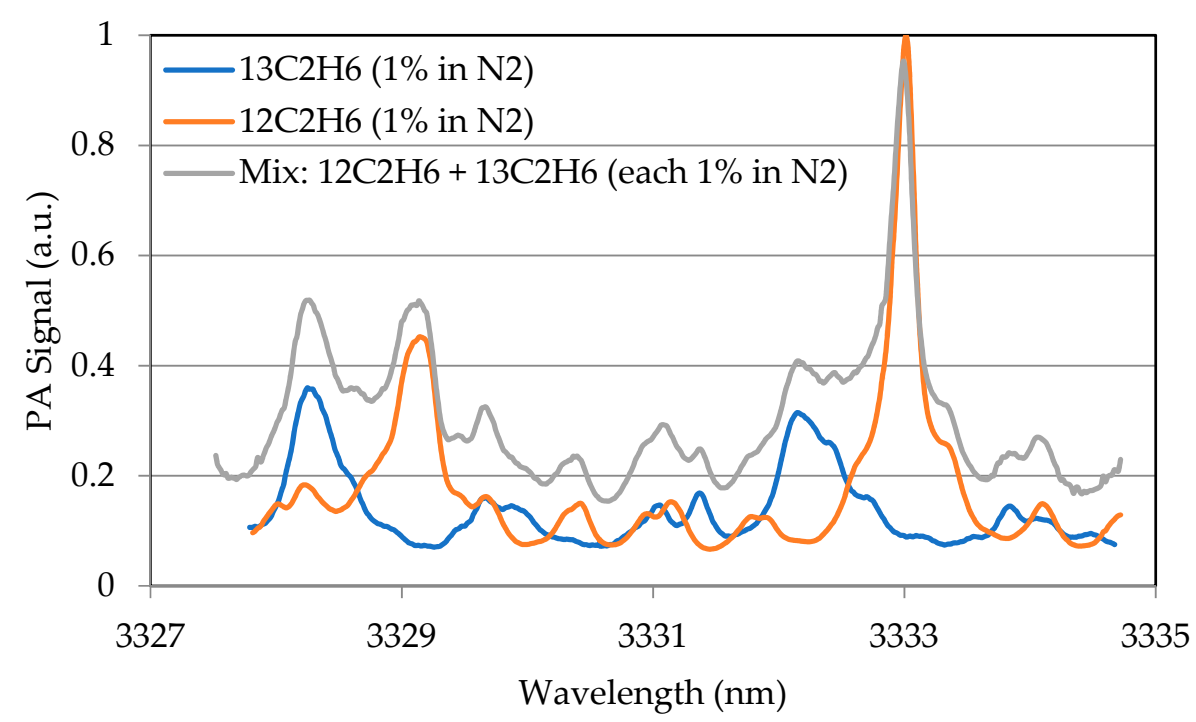

Figure 2. Photoacoustic spectra of ${ }^{12} \mathrm{C}_{2} \mathrm{H}_{6},{ }^{13} \mathrm{C}_{2} \mathrm{H}_{6}$ and a mixture of both isotopologues (ca. $20{ }^{\circ} \mathrm{C} ; 1013$ $\mathrm{hPa})$.

\section{Conclusions}

The new optical analyzer is compact and robust and allows the measurement of hydrocarbon isotopologues directly, in real-time and in-situ for various applications. The detection sensitivity is in the parts-per-million range.

Author Contributions: Conceptualization, M.W.; methodology, A.L. and M.W.; formal analysis, A.L.; investigation, A.L.; data curation, A.L.; writing - original draft preparation, M.W.; writing - review and editing, A.L. and M.W.; visualization, A.L. and M.W.; supervision, M.W.; project administration, M.W.

Funding: This research received no external funding.

Conflicts of Interest: The authors declare no conflict of interest.

\section{References}

1. Atkinson, R. Gas-phase tropospheric chemistry of organic compounds: A review. Atmos. Environ. Part A. General Topics 1990, 24, 1-41.

2. Faramawy, S.; Zaki, T.; Sakr, A.-E. Natural gas origin, composition and processing: A review. J. Nat. Gas Sci. Eng. 2016, 34, 34-54.

3. Villanueva, G. L.; Mumma, M. J.; Magee-Sauer, K. Ethane in planetary and cometary atmospheres: Transmittance and fluorescence models of the $v 7$ band at $3.3 \mu \mathrm{m}$. J. Geophys. Res. 2011, 116, E08012.

4. Witinski, M.F.; Sayres, D.S.; Anderson, J.G. High precision methane isotopologue ratio measurements at ambient mixing ratios using integrated cavity output spectroscopy. Appl. Phys. B 2011, 102, 375-380.

5. Saito, T.; Stein, O.; Tsunogai, U.; Kawamura, K.; Nakatsuka, T.; Gamo T. et al. Stable carbon isotope ratios of ethane over the North Pacific: Atmospheric measurements and global chemical transport modeling. J. Geophys. Res. 2011, 116, D02308.

6. Rudolph, J.; Czuba, E. On the use of isotopic composition measurements of volatile organic compounds to determine the "photochemical age" of an air mass. Geophys. Res. Lett. 2000, 27, 3865-3868.

7. Saito, T.; Kawamura, K.; Tsunogai, U.; Chen, T.-Y.; Matsueda, H.; Nakatsuka T., et al. Photochemical histories of nonmethane hydrocarbons inferred from their stable carbon isotope ratio measurements over east Asia. J. Geophys. Res. 2009, 114, D11303.

8. Sessions, A.L. Isotope-ratio detection for gas chromatography. J. Sep. Sci. 2006, 29, 1946-1961.

9. Loh, A.; Wolff, M. Absorption cross sections of ${ }^{13} \mathrm{C}$ ethane and propane isotopologues in the $3 \mu \mathrm{m}$ region. JQSRT 2017, 203, 517-521.

10. Vurgaftman, I., et al. Interband cascade lasers. J. Phys. D: Appl. Phys. 2015, 48, 123001. 
11. Wolff, M.; Rhein, S.; Bruhns, H.; Nähle, L.; Fischer, M.; Koeth, J. Photoacoustic methane detection using a novel DFB-type diode laser at $3.3 \mu \mathrm{m}$. Sens. Actuator B: Chem. 2013, 187, 574-577.

12. Bell, A.G. On the production and reproduction of sound by light. AJS 1880, 3, 305-324.

13. Michaelian, K.H. Photoacoustic IR spectroscopy, Wiley-VCH: Weinheim, Germany; [Chichester, England], 2010.

(C) 2018 by the authors. Licensee MDPI, Basel, Switzerland. This article is an open access article distributed under the terms and conditions of the Creative Commons Attribution (CC BY) license (http://creativecommons.org/licenses/by/4.0/). 